\title{
Survivorship vs. Extinction at the KPg \\ Boundary: An isotopic look at vital effects in bivalves
}

\author{
SIERRA V PETERSEN ${ }^{1}$, ALLISON N CURLEY ${ }^{1}$, \\ STEWART M EDIE ${ }^{2}$, RACHEL C MOHR ${ }^{3}$, ELIZABETH \\ OLIPHANT $^{1}$ AND THOMAS TOBIN $^{3}$ \\ ${ }^{1}$ University of Michigan \\ ${ }^{2} \mathrm{NMNH}$, Smithsonian Institution \\ ${ }^{3}$ University of Alabama \\ Presenting Author: sierravp@umich.edu
}

A persistent question in paleontology, and earth science generally, is why certain taxa survive mass extinctions when the overwhelming majority of taxa become extinct. Resilience and flexibility in the face of changing environmental conditions may improve a species' ability to survive some drivers of mass extinction. Here, we present a unique geochemical dataset documenting differences in isotopic and trace elemental compositions $\left(\delta^{18} \mathrm{O}, \delta^{13} \mathrm{C}, \Delta_{47}\right.$, and $\left.\mathrm{Sr} / \mathrm{Ca}\right)$ of inner vs. outer shell layers in five genera of marine bivalves living on Seymour Island, Antarctica, around the time of the Cretaceous-Paleogene (KPg) mass extinction. We discuss possible mechanisms driving these chemical differences and relate them to survivorship across the KPg boundary. The two genera in which we observe the largest isotopic differences between the inner and outer shell layers survive across the boundary, while the three genera that go extinct show little to no inter-layer differences. Chemical differences between shell layers may indicate a taxon's ability to modulate the chemistry of its internal body fluid and induce "vital effects" in precipitated shell material. This flexibility may increase the likelihood of survival under adverse environmental conditions. This study presents a new way to look at intra-shell variations in geochemistry and aims to turn "vital effects" from an obstacle in paleoproxy studies to a new tool. 